\title{
Pulmonary Metastasis of a Prostate Adenocarcinoma within a Primary Lung Adenocarcinoma: A Tumor-to- tumor Metastasis Case Report
}

Metástase Pulmonar de um Adenocarcinoma da Próstata dentro de um Adenocarcinoma Pulmonar Primário: Relato de Caso de uma metástase de tumor-para-tumor

André Marcondes Braga Ribeiro ${ }^{1, *}$, Ana Luiza Tatarin Vivan¹, Eduardo Nóbrega Pereira Lima', Maria Nirvana da Cruz Formiga², Mauro Daniel Spina Donadio², Felipe D’Almeida Costa ${ }^{3}$.

\begin{abstract}
Applications for ${ }^{68} \mathrm{Ga}$-PSMA PET-CT continue to expand beyond prostate cancer. The objective of this case report is to illustrate a rare phenomenon known as tumor-totumor metastasis in which precise histological diagnosis is an essential prerequisite for correct clinical management of patients. A 89-year-old man with prostate cancer underwent ${ }^{68} \mathrm{Ga}$-PSMA PET-CT study for rescreening after increasing prostate specific antigen (PSA), revealing abnormal uptake of the radioindicator in the prostate and bilateral lung nodules. A biopsy was performed on one of the left lung nodules and the results of the pathology examination revealed that the lesion consisted of metastatic prostatic adenocarcinoma within a primary lung adenocarcinoma.
\end{abstract}

Keywords: Neoplasm Metastasis; PROSTATE; LUNG.

\begin{abstract}
RESUMO
As aplicações para o PET-CT com ${ }^{68} \mathrm{Ga}$-PSMA continuam a se expandir além do câncer de próstata. O objetivo deste relato de caso é ilustrar um fenômeno raro conhecido como metástase de tumor-para-tumor em que o diagnóstico histológico preciso é um pré-requisito essencial para o correto manejo clínico dos pacientes. Um homem de 89 anos com câncer de próstata foi submetido ao estudo de PET/CT com ${ }^{68} \mathrm{Ga}$-PSMA para reestadiamento após apresentar aumento do antígeno específico da próstata (PSA), revelando captação anormal do radioidicador na próstata e em nódulos pulmonares bilaterais. Uma biópsia foi realizada em um dos nódulos do pulmão esquerdo e os resultados do exame anatomopatológico revelaram que a lesão consistia em um adenocarcinoma prostático metastático dentro de um adenocarcinoma de pulmão primário.
\end{abstract}

Descritores: ${ }^{68 G a-P S M A ; ~ M e t a ́ s t a s e ~ d e ~ t u m o r-p a r a-t u m o r ; ~ C a ̂ n c e r ~ d e ~ p r o ́ s t a t a ; ~ C a ̂ n c e r ~ d e ~}$ pulmão.

1. A.C.Camargo Cancer Center, Nuclear Medicine - São Paulo - SP - Brazil

2. A.C.Camargo Cancer Center, Clinical Oncology - São Paulo - SP - Brazil

3. A.C.Camargo Cancer Center, Pathology - São Paulo - SP - Brazil

Financial support: none to declare.

Conflicts of interest: The authors declare no conflict of interest relevant to this manuscript.

Correspondence author: André Marcondes Braga Ribeiro. A.C.Camargo Cancer Center.

Rua Tamandaré, 753. Liberdade, São Paulo, SP, Brazil. Zip code: 01525-001. Phone: +55 11999093718.

E-mail: andre_mbr@hotmail.com.

Received on: April 4, 2019 | Accepted on: April 24, 2019

DOI: $10.5935 / 2526-8732.20190010$ 


\section{INTRODUCTION}

"Tumor-to-tumor metastasis" is a rare phenomenon, described in few reports in the literature, in which a tumor metastasizes and its growth is established in another tumor. ${ }^{1}$ Lung carcinoma is the most frequent donor tumor, but it is extremely rare as recipient. ${ }^{2}$
In this report we describe, for the first time, a case of this combination of donor and recipient tumors: metastasis from prostatic adenocarcinoma to lung adenocarcinoma. Histological analysis was conducted after ${ }^{68} \mathrm{Ga}$-PSMA PET-CT found evidence of pulmonary nodules in a patient with a diagnosis of prostate cancer undergoing restaging after biochemical relapse.

\section{PRESENTATION OF THE CASE}

The patient was an 89-year-old male with previous low charge of smoking (less than 10 years-package) and who had been diagnosed in 2005 with adenocarcinoma of the prostate, graded at Gleason $8(4+4)$, and underwent radical prostatectomy the same year. In 2009, biochemical and local relapse were detected and he was treated with salvage radiotherapy combined with hormone therapy. In July 2018, biochemical relapse was detected again with PSA level raising from 2.79 to 3.84 plus lung lesions in a castrationresistant scenario and it was started abiraterone acetate as systemic treatment. The ${ }^{68} \mathrm{Ga}-\mathrm{PSMA}$ PET-CT imaging was used for restaging, revealing anomalous tracer concentrations in the prostatic space, with an SUV of 2.6; in a left peribronchial mass, with an SUV of 8.0; and in multiple bilateral pulmonary nodules with SUVs ranging from 2.8 to 4.4. (Images 1, 2 and 3).

A biopsy was then performed on one of the nodules in the patient's left lung (Image 4). Three fragments were obtained from a transthoracic core biopsy and all of them showed malignant epithelial cells infiltrating a desmoplastic stroma, arranged in a predominant acinar pattern, with focal cribriform structures (Images 5A and 5B). Since the patient had a history of prostate cancer, an immunohistochemical study was performed. Most of the malignant glands stained diffusely positive for TTF-1 (nuclear staining) (Image 5C) and Napsin-A (granular cytoplasmic) (Image 5D), both markers of pulmonary adenocarcinoma. There was a small group of acini that were negative for these markers. These glands were positive for NKX3.1 (nuclear staining) (Image 5E) and PSA (granular cytoplasmic) (Image 5F), indicating prostatic origin. Taking all these findings into account, the final diagnosis was metastatic prostatic adenocarcinoma within a lung adenocarcinoma (tumor-to-tumor metastasis). It was proposed maintenance with current hormone therapy for prostate cancer and driven-mutation test for target therapy against lung cancer.

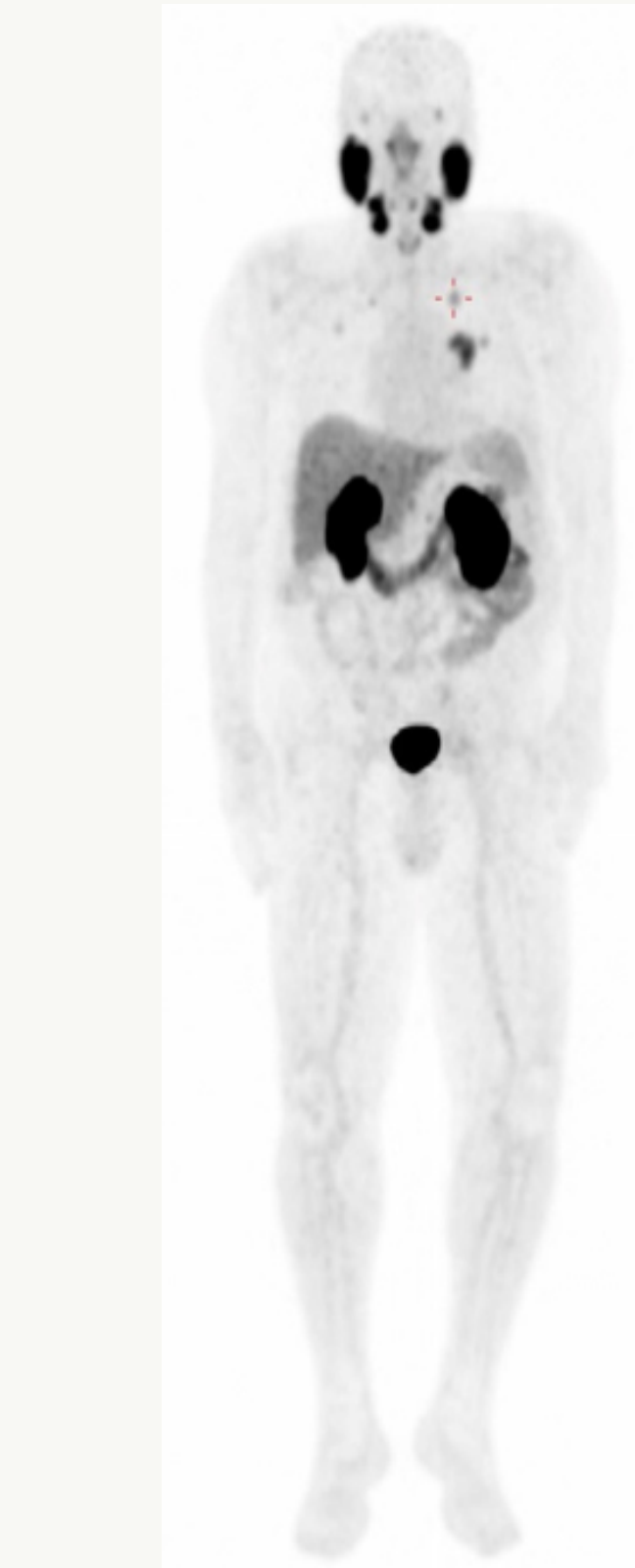

Image 1. Full body image at maximum intensity projection (MIP) from the PET-CT examination, demonstrating areas of abnormal 68Ga-PSMA concentration in the lungs, especially the left lung nodule that was biopsied (cross). 

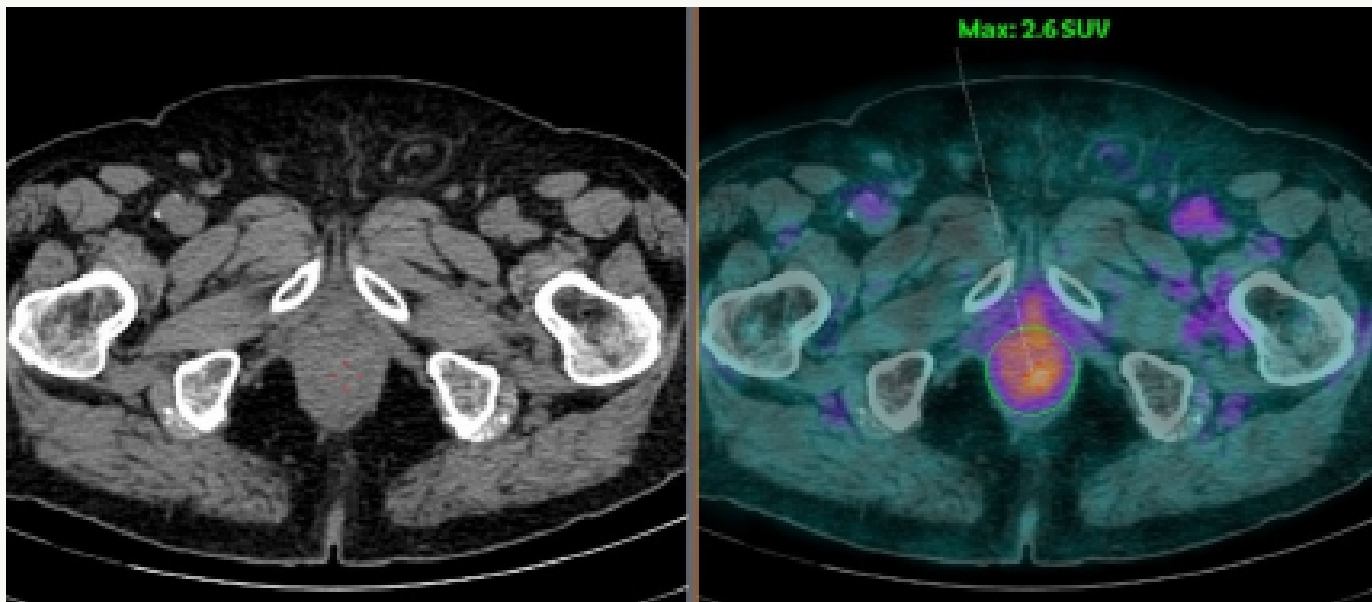

Image 2. Axial slices from low dose CT (on the left) and coregistered PET-CT (on the right) demonstrating 68Ga-PSMA concentrations in the prostate space with an SUV of 2.6.
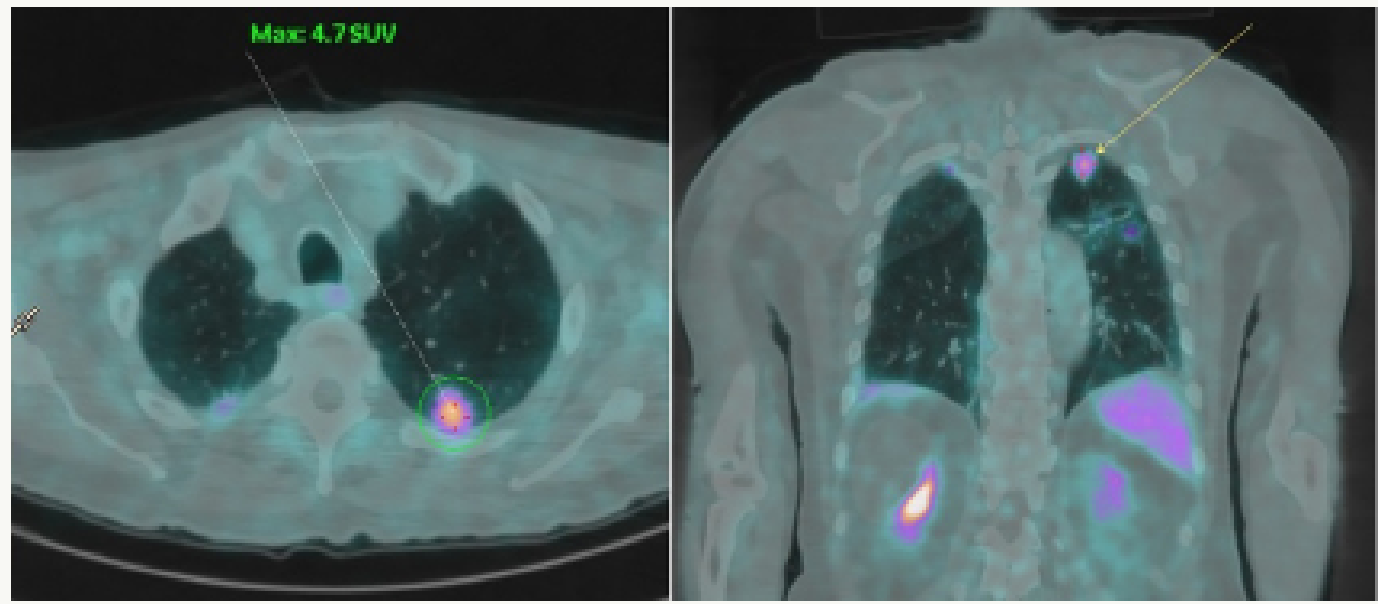

Image 3. Coregistered PET-CT axial slices (on the left) and coronal slices (on the right) demonstrating 68Ga-PSMA concentrations in the left lung nodule (which was later biopsied) with an SUV of 4.7.

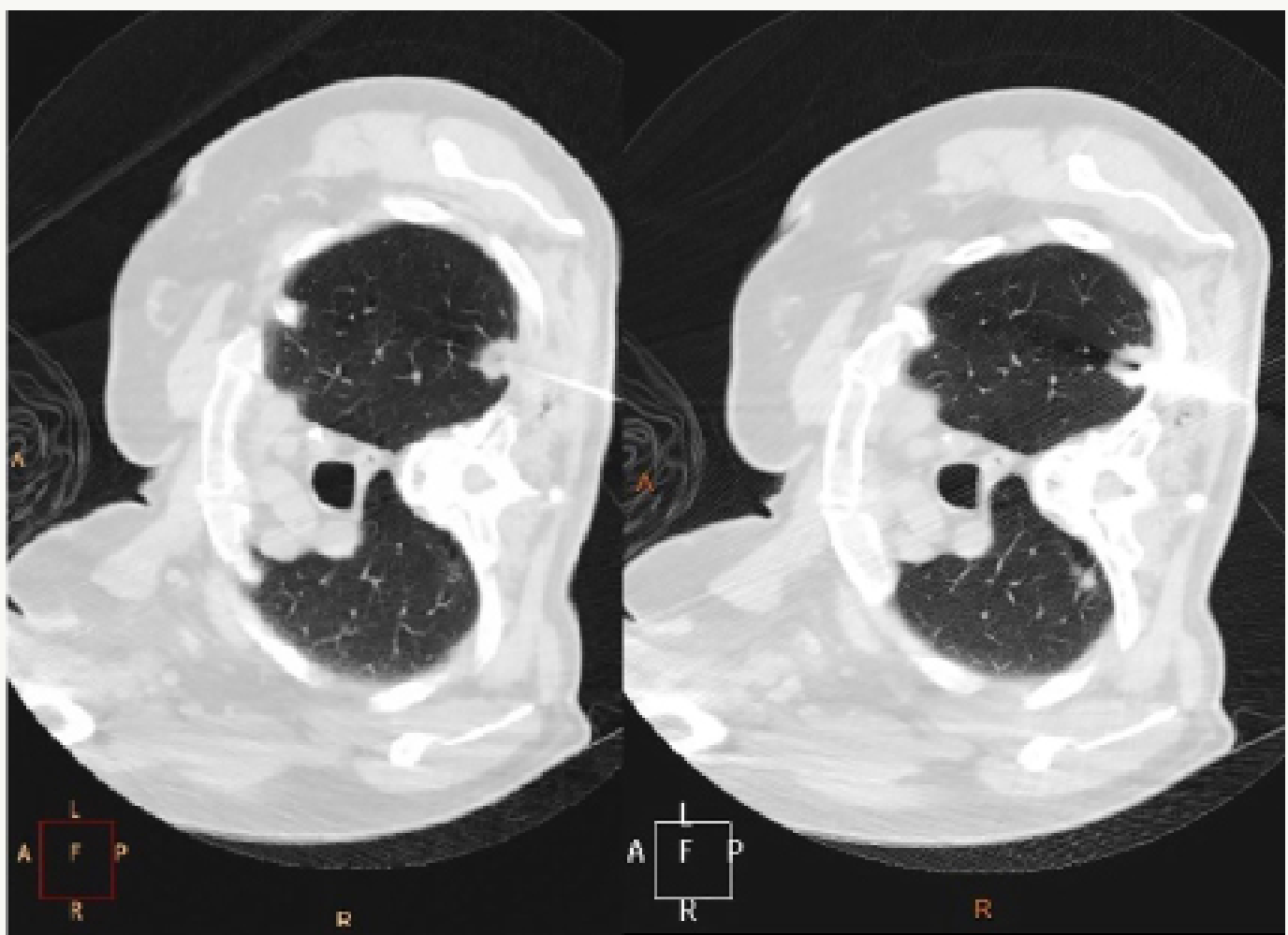

Image 4. Axial computed tomography slices guiding the biopsy of left lung nodule using a large caliber needle with a Coaxial 17 / 18 G system and automatic trigger device. 


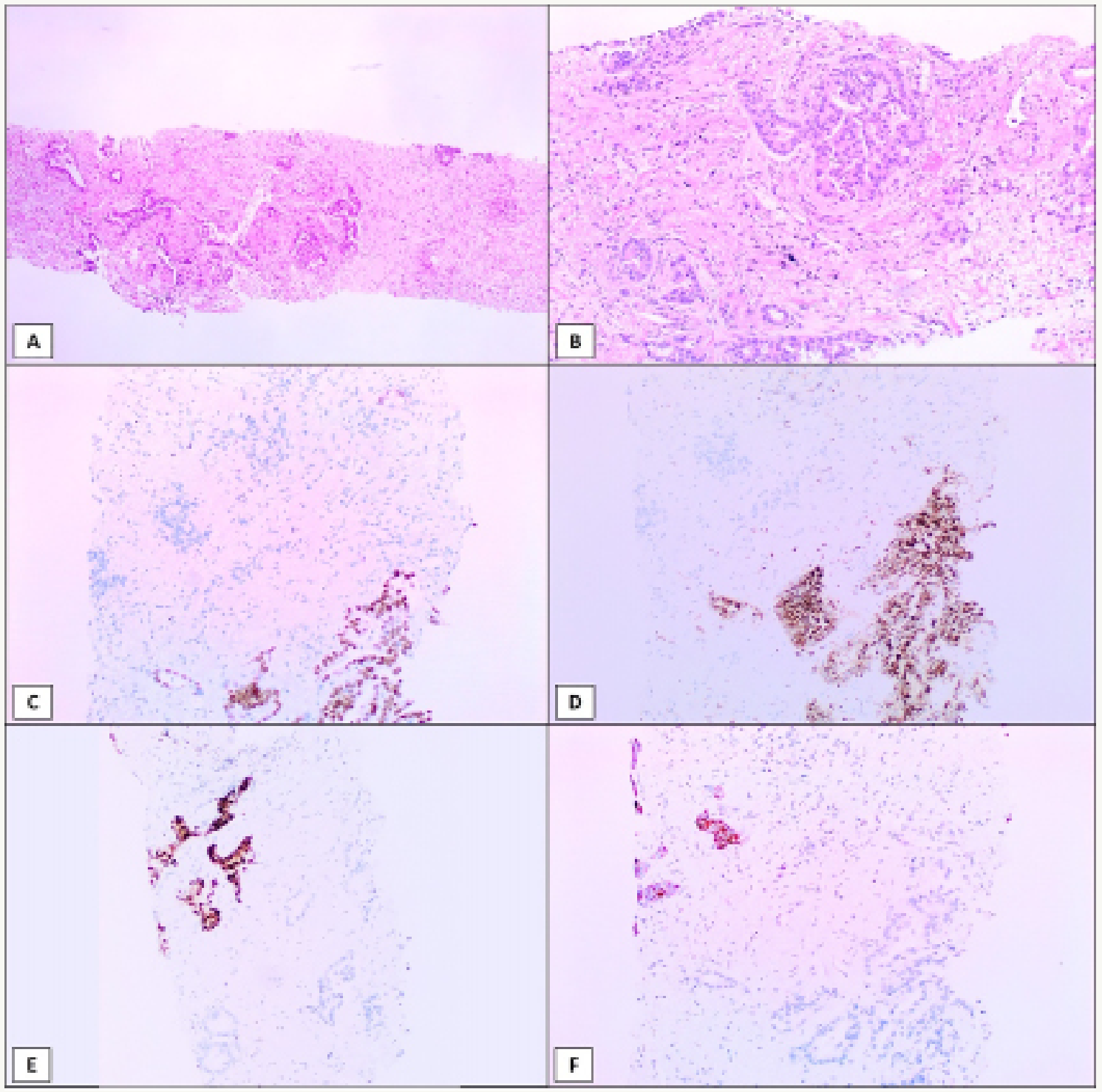

Image 5. A) Biopsy fragments showing an infiltrating adenocarcinoma (H\&E, 40x). B) The tumor was composed of acinar and cribriform malignant glands (H\&E, 100x). Most of the tumor cells were positive for TTF-1 (C, 100x) and Napsin-A (D, 100x), but a small group of cells were negative for both markers (upper left corner). In contrast, those glands were positive for NKX3.1 (E, 100x) and PSA (F, 100x), mirroring the images from the lung markers and confirming the diagnosis of a metastatic prostatic adenocarcinoma inside a primary lung tumor.

\section{DISCUSSION}

"Tumor-to-tumor metastasis" is a phenomenon that is still considered rare in the literature and, according to Campbell et al., certain criteria must be met for diagnosis: more than one primary tumor; the recipient tumor must be a true benign or malignant neoplasm; metastatic growth must be established in the recipient tumor; and tumors that have metastasized to the lymphatic system are excluded. ${ }^{3}$

Just as there are differences in metastatic potential between different tumors, there are also differences in their capacity to host metastases. According to the literature, clear cell renal cell carcinoma is the most common metastasis recipient tumor, followed by sarcoma, meningioma, and thyroid cancer.
Lung carcinoma is the most common donor tumor (40-50\% of cases), followed by breast, gastrointestinal tract, prostate, and thyroid carcinomas. ${ }^{4}$

Lung carcinoma as recipient of tumor metastasis, as described in this case, is one of the rarest presentations. The most common donor tumor for this recipient is papillary thyroid carcinoma. In addition to not affording a rich network of blood vessels, they tend to grow rapidly and do not provide a suitable host environment. ${ }^{2}$ Moreover, prostatic metastasis to normal pulmonary parenchyma, in the absence of other metastatic sites, is itself a rare finding. ${ }^{5}$

Applications for ${ }^{68} \mathrm{Ga}-\mathrm{PSMA}$ PET-CT continue to extend beyond prostate cancer. Expression of PSMA has been demonstrated by immunohistochemistry 
in neovasculature of a range of lung tumors that exhibited affinity with ${ }^{68} \mathrm{Ga}$-PSMA. However, this analytical method is not yet able to discriminate reliably between pulmonary lesions in patients with prostate cancer. Primary lung tumors have demonstrated similar tracer concentrations to prostatic metastases, creating a diagnostic challenge that, in the majority of cases, still requires histological confirmation. ${ }^{6}$
Ethical Considerations: This case report received approval from the institution's Research Ethics Committee.

Conflict of Interest Statement: The authors declare that the research was conducted in the absence of any commercial or financial relationships that could be construed as a potential conflict of interest.

Acknowledgments: None.

\section{AUTHOR'S CONTRIBUTION}

André Marcondes Braga Ribeiro: Collection and assembly of data, Conception and design, Data analysis and interpretation, Final approval of manuscript, Manuscript writing.

Ana Luiza Tatarin Vivan: Conception and design, Data analysis and interpretation, Final approval of manuscript, Manuscript writing.
Eduardo Nóbrega Pereira Lima: Collection and assembly of data, Conception and design, Data analysis and interpretation.

Maria Nirvana da Cruz Formiga: Data analysis and interpretation, Final approval of manuscript, Manuscript writing.

Felipe D ' Almeida Costa: Collection and assembly of data, Data analysis and interpretation, Final approval of manuscript.

\section{REFERENCES}

1. Lee T, Cha YJ, Ahn S, Han J, Shim YM. A Rare Case of Tumor-To-Tumor Metastasis of Thyroid Papillary Carcinoma within a Pulmonary Adenocarcinoma. J Pathol Transl Med. 2015;49(1):78-80.

2. Xue L, Luan Z, Liu Y, Zou S, Jiang J, Wu N, et al. Pulmonary metastasis of papillary thyroid carcinoma and primary lung adenocarcinoma: two coincident carcinomas at the same location. Diagn Pathol. 2013;8:26.

3. Lowenthal BM, Fadare O. The Rare Phenomenon of Tumor-to-Tumor Metastasis. Int J Surg Pathol. 2017;25(1):63-4.
4. Petraki C, Vaslamatzis M, Argyrakos T, Petraki K, Strataki M, Alexopulos C, et al. Tumor to tumor metastasis: report of two cases and review of the literature. Int J Surg Pathol. 2003;11(2):12735.

5. Reinstatler L, Dupuis J, Dillon JL, Black CC, Phillips JD, Hyams ES. Lung malignancy in prostate cancer: A report of both metastatic and primary lung lesions. Urol Case Rep. 2018;16:119-22.

6. Pyka T, Weirich G, Einspieler I, Maurer T, Theisen J, Hatzichristodoulou G, et al. 68Ga-PSMA-HBEDCC PET for Differential Diagnosis of Suggestive Lung Lesions in Patients with Prostate Cancer. J Nucl Med. 2016;57(3):367-71. 